\title{
EXAMINING IMPACTS OF Big DATA ANALYTICS ON CONSUMER FinANCE: A CASE OF CHINA
}

\author{
Jiwat $^{1}{ }^{1}$ and Hong Yang ${ }^{2}$ \\ ${ }^{1}$ School of Management, Shandong University, Jinan, China \\ ${ }^{2}$ IBSS, XJTLU, China
}

\begin{abstract}
The use of Big Data analytics for business improvements is a vital strategy for survival. In this paper, we report a study that investigates the role of BD analytics on consumer finance, credit card finance in China-a research area that has largely remained unexplored. The largeness and diversity of Chinese consumer market merit an urgent attention and understanding of role of BD analytics is significant both theoretically and managerially. This study achieves that target. Given the exploratory nature of study, we take a qualitative approach. We conduct approximately 30 interviews with baking and finance sector respondents. The data will be recorded, transcribed and translated. We will analyze data using content analysis / thematic analysis technique.
\end{abstract}

\section{KEYWORDS}

Consumer finance; Credit Card finance; Business analytics China

\section{INTRODUCTION}

Big data is another name of large set of massive data that are useful but challenging to process using traditional means (Crosman 2012). Big data analytics refers to the process of extracting useful business information through a combination of software tools and algorithms. With the development of advanced technology, the threshold of processing data has become blur allowing organizations to use a variety of approaches to handle and analyze unstructured and semistructured data (Kugel 2013). It is estimated that there are 1.35 billion customers and 618 million Internet users in China, and the value of China's information data market could be over 3.2 trillion yuan in 2015 (Yao, 2014).

Consumer finance, which refers to short-term loans for personal consumption of durable goods or services has become a promising industry in China (Li 2012). According to Przzom (2012), during 2007 to 2011 period the compound annual growth rate (CAGR) of consumer finance market in China was $28.33 \%$ perhaps due to expanded domestic demand for consumer products. Thus, the development of domestic demand in China could enhance the opportunity for consumer finance market, especially for lending activities, to develop.

Credit card loan is increasingly becoming popular in consumer finance market in China, because of high profit and growth rate. Resultantly banking sector is concentrating heavily on credit card offerings to enhance business performance (Hughes 2016). Although banks in China are eager to collect consumers information to produce tailored 
products, the lack of reliable consumer credit evaluation and risk management abilities could be an obstacle for further developments of banking sector (China Daily 2004, 2015).

Big data analytics could help banking sector to build and offer innovate financial products and services that meet consumer needs, help improve management of risks of default, make better decisions, and thus enhance business performance (McMalcolm 2015, Manyika et al. 2011, Kambatla et al. 2014, Spotfire Blogging Team 2013). Despite usefulness of BD analytics existing research on the advantages of big data for improvements in consumer finance is in its infancy and practical applications of big data analytics for enhancements in credit card offerings in China remain largely unknown. While some research highlight the performance of commercial banks in using big data analytics, specific research on the operation and use of big data analytics for credit card offerings merit further attention. This research, therefore, fills the gap in knowledge by investigating the implications of big data analytics on consumer finance especially for credit card offerings in China. The research question is:

What are the implications of big data analytics on consumer finance in banking sector such as credit card offerings?

This research is significant in not only investigating an issue in a largely unexplored research strand but also in providing an understanding to managers on how BD analytics can help in developing solutions in consumer finance segment with tailored credit card offerings. The research will be able to build knowledge on how could banking sector differentiate among various consumer groups and gather right consumer data, ensure security of consumers' information, cope with the analytics skill deficiencies and make rational decisions. The results can be used for making long-term strategies for credit card offerings and improvements in business performances with enlarged product portfolios and revenues.

\section{RELATED WORK}

\subsection{CONSUMER FinAnCE In CHINA}

Consumer finance refers to personal lending activities of durable goods and services, including credit cards, mortgage, and automotive finance ( $\mathrm{Li} 2012$ ). Although consumer finance with low current penetration in China shows a lack of development compared to developed countries, but with a large population combined with urbanization activities consumer finance industry in China is promising industry. As Chinese government is planning to shift GDP growth focus from exports to domestic consumption, consumer lending will become a significant sector (Li 2012).

\subsection{CREDit CARD OFFERINGS IN BANKING SECTOR IN CHINA}

Credit card loans are becoming increasingly popular among Chinese with 15.2 trillion yuan credit card payments by 2014 and high volume growth (China Daily, 2015). Credit card loan is a fastgrowing type of loan in consumer finance, with the low initial base, which also implies that this classification of loan will show its potential to grow in the future (Przoom 2012).

Hughes (2016) highlighted the importance by suggesting that credit card loan is a highly profitable project for banks and one way to build loyal credit card customers is to establish strong relationship with consumers assisted by big data analysis. To provide tailored services to customers, to increase credit card holders' portfolio and increase the consumption by cardholders, banks are eager to analyse target consumers' preferences and creditworthiness. However, as China's consumer credit evaluation system and analytics ability is still very nascent and not welldeveloped, banks lack the ability to track records of the financial products they offered to 
International Journal of Managing Information Technology (IJMIT) Vol.9, No.3, August 2017

customers, banks might lend too much money to those who have weak creditworthiness (China Daily 2004). In addition, according to a report of China Daily (2015), the rising risks of delay repayment for more than half a year is 42 percent, thus banking sector needs to consider the risk management in credit card loans.

As consumer finance companies and Internet-based financial institutions, the non-banking institutions, fiercely compete to capture the market share, banks should find an efficient approach to enhance businesses performance to maintain market share. In this context, banks have already deployed various strategies such as offering discount on travel routes, offering cash rebates, providing discount on flights, hotel bookings and car rentals, providing various kinds of special treatment to customers, and creating online channels to attract potential customers who own mobile phones (Jiang 2016).

\subsection{Role Of Big Data Analytics On Consumer Finance}

According to Kambatla et al. (2014), if a retailer could fully leverage the potential of big data analytics, it could increase its operation margin by at least 60 percent. Big data analytics enables businesses to access and analyze multiple data sources with rapid speed, improve decision making, develop tailored services that meet consumer needs, and obtain better judgement of lending activities thus minimizing losses (McMalcolm 2015).

Using big data analysis could assist banking sector to obtain competitive advantage in many ways. First, it could provide tools and methods for banks to access data and perform analytics in minimum amount of time and easy processes (Manyika et al. 2011). Second, big data analytics could enhance the predictive accuracy of future business plan outcomes by using historical data (Groenfeldt nd). Third, big data analytics allows banks to innovate tailored products that could meet the changing requirements of customers through understanding of specifics of customer behaviours and patterns (Manyika et al. 2011). Fourth, as the market and consumer behaviors involve many uncertainties, banks could use big data analytics to track consumer transactional behaviors and manage risks of default (Spotfire Blogging Team 2013; Fang \& Zhang, 2016). Finally, BD analytics can help banking sector to save cost of tracking and monitoring consumers' information and reduce potential losses from defaulting (Kshetri, 2016).

Particularly with the help of big data analytics, banking sector is able to transform the semistructured and un-structured data into structured data using algorithms and then analyse for business performance improvements (Marr 2016). Banks generate data through multiple channels, such as offline consumption and online transactions (Sen 2014). In this way, banks are able to segment data and track typical customers' financial transaction behaviors across various segmentations to provide personalized services, and build and maintain loyal customer base (Bagchi 2014).

Moreover, a 2010 global fraud study showed that banking and financial services industry dealt with more than 16 percent of fraudulent transactions, thus fraud detection is vital to banking sector development. With advanced BD analytics, banks could scan historical records of consumers to identify abnormal variabilities and even could predict the default risk of consumers, and thus manage market uncertainties and control exposure risk (Pramanick 2013, Marr 2016; Groll et al., 2015).

Despite its advantages, big data analytics also faces many challenges, for instance, choosing the right data sources, the safety of data storage and the gaps in skill for big data analytics (Elan financial services nd, Bagchi 2014). 
International Journal of Managing Information Technology (IJMIT) Vol.9, No.3, August 2017

\subsection{Big DATa Implications ON CREDit CARD OfFERINGS In China}

Commercial banks, as the leaders of credit market, especially CITIC bank and ICBC (Industrial and Commercial banks of China) in China have pursuing opportunities to building close relationship with consumers. CITIC bank uses SAS (statistical analysis system) and Pivotal Greenplum Database to establish open-platform and improve business performance (Pivotal nd). With the help of advanced data system, CITIC bank is able to provide improve productivity through a customer contact center, maximize marketing campaigns, accelerate data analytics speed and avoid risks. In addition, although ICBC has developed e-payment and online financing system and managed over 100 billion yuan transactions through their e-commerce platform, it is significant for ICBC to use big data analytics to offer suitable financial services (Jiang 2015).

Though banks in China are recognizing the benefits generated from big data applications and are trying to harness the potential, there is still little research that provides specific explanation of how big data analytics is used in credit card offerings for consumer finance in China.

To sum up, based on an extensive review of the literature it could be concluded that the implication of big data on consumer finance such as credit card offerings has not been researched, not just in global banking context but also in Chinese context. Banking and finance is considered vital to economy and society and consumer finance plays a significant role in banking operations, meriting further investigations. Given the gap, we investigate the role and implications of BD analytics on consumer finance through credit card offering from a Chinese perspective.

\section{Methodology}

Given the exploratory nature of research, we will take a qualitative approach to the study. The research process is divided into three parts - questionnaire design, data collection and data analysis. We conducted an extensive review of literature to identify key issues related to credit card finance and constructed a semi-structured questionnaire to seek respondents' opinions on how BD analytics can help improve the identified issues. Such an approach will help us understand the implications in areas such as classification of consumer groups, approaches that banks could take to analyze transaction data, techniques of using big data analytics to obtain consumers' preference and predict potential risk, the processes that banks use to develop credit card offering strategies.

The study will conduct an approximately 30 interviews with target respondents form a variety of occupational backgrounds such as commercial banks' senior managers and financial service industry experts in China. We will use both, online system such as Sojump, or hand-delivered methods to conduct interviews, either face-to-face or by online software (e.g. Skype or WeChat). Interviews will be recorded with respondents' permission, and transcribed. Because the majority of target respondents are Chinese, researcher will translate the Chinese data into English version.

We will analyse the data using Nvivo 10 and content analysis methods. It will enable us to analyze information from interviews, notes of observations with less time and high quality (Hilal and Alabri 2013).

\section{INSTRUMENT DEVELOPMENT}

The instrument development work involved a thorough review of the existing literature on Big Data implications and the Consumer Finance. To perform a structured literature review we conducted search of five database, namely, ScienceDirect, Emerald, Google Scholar, EBSCO Academic Search Complete, and JSTOR. We used a number of key-words to identify the relevant literature. List of Key-words used is shown in Table 1. 
International Journal of Managing Information Technology (IJMIT) Vol.9, No.3, August 2017

The search of literature using these keywords led to identification of a number of articles. These articles were reviewed for their relevance and appropriateness. Initially, we screened these articles by reading the abstract. If we find the abstract relevant we further reviewed the articles.

The detailed reading of articles then helped us identify a number of issues related to implications of Big Data for consumer finance industry. These issues and themes were then converted into specific variables to be measured. These variables led to development of semi-structure questionnaire for interview purposes.

\begin{tabular}{|l|}
\hline \multicolumn{1}{|c|}{ Key words } \\
\hline big data analytics in finance \\
\hline big data + consumer finance \\
\hline big data analytics + credit cards \\
\hline big data analytics + credit card facility \\
\hline Mastercard big data \\
\hline Implications of Big Data + Consumer Finance \\
\hline Big Data technology + implications \\
\hline Mastercard data analytics \\
\hline Credit card transaction data analytics \\
\hline Mastercard data monetization \\
\hline Consumer Finance in China \\
\hline Banking sector + Big Data \\
\hline Big Data + Credit card offerings \\
\hline \hline Banking sector lending activities \\
\hline Credit card products + Big data analytics \\
\hline
\end{tabular}

The survey questionnaire as developed through above process consisted of mainly two parts.

(1) Part I: It included questions to collect respondents' information. These questions were:

1. Respondents' Name

2. Job Title

3. Job Duty

4. Organization details

a. Name of Organization

b. Type of Organization

c. Size of Organization (Number)

i. $\quad 0-19$

ii. $\quad 20-99$ 
International Journal of Managing Information Technology (IJMIT) Vol.9, No.3, August 2017

iii. $\quad 100-200$
iv.

d. Location of Organization

(2) Part II: It included questions on a number of issues related to Big Data implications for consumer finance as discussed below.

\section{A. Big Data Analytics To Enhance Credit Card Business Profits}

One of the key benefits of Big Data analytics as emerged from the literature was that Big Data can help in enhancing the efficiencies of credit card offerings and ultimately result in enhancing the profitability (Kambatla et al. 2014). Therefore, a question seeking respondents' views was included in the questionnaire to gain an indepth understanding of such an implication.

\section{B. IMPlication Of Big DATA For MAKing Decisions}

Big Data analytics can help in enhancing decision making. A number of organisations use this as a motivation to launch Big Data analytics projects (Gascon, 2015). This study sought to understand how Big Data can help in improving decision making for credit card business. Specifically, Big Data analytics can help in improving decision making for new credit card product launch, developing credit card fees structure, promotions and service delivery.

\section{IMPlication Of Big DATa For Developing STRATEgies}

One of the implications of Big Data has been its potential for helping organisations develop new business strategies (Gascon, 2015). This is very relevant to Banking and Consumer finance industry as banks have to keep pace with the changing demands of consumers. This study sought to understand from our respondents' as to how Big Data analytics can actually help in developing new strategies for credit card products.

\section{Understanding Consumers' Behaviours}

Organisations including Banking and Financial institutions collect a large amount of data about customer transactions and the patterns and behaviours of customers in managing their financial needs. The data collected as such could provide critical insights in understanding customer changing behaviours. Such changes then need to be translated into changes in products, services and overall operational routines (Bagchi, 2014). We, therefore, sought to enquire from our respondents as to how Big Data analytics can actually help in understanding credit card consumer behaviours and how that understanding can be translated into adjustments of offerings and operational routines.

\section{E. Classifying Customers Into Different Groups}

Classifying customers into different groups could help in enhanced credit card offerings (Bagchi, 2014). The segregation of customers into income, age, gender, spending habits, location could help in improving credit cards products and service delivery. Banking industry is fortunate in a way that it is accessed by all types of customers. Such a situation results into collection of 
International Journal of Managing Information Technology (IJMIT) Vol.9, No.3, August 2017

customer data that can be analysed using Big Data technology to enhance customer services. We, therefore, sought to understand from our respondents as to how segregation of customers could help in enhancing their credit card products and operations as a whole.

\section{F. ENHANCE RELATIONShiP With CUSTOMERS AND RETAin CuSTOMERS}

Customer retention is considered one of the critical activities as cost of acquiring new customers is often very high. Organisations including Banking sector organisations therefore make efforts to retain their existing portfolio of customer and take measure to enhance customer relations (Hughes, 2016). Big Data technology can help banking organisations in analysing the data on loyal customers versus those who left for other banks. Such an analysis could help banking organisation to proactively monitor and enhance customer relation and improve profitability. This study, therefore, sought to understand from their clients as to how Big Data analytics can help in improving customer relationship and customer retention.

\section{G. Cost SAving}

One of the features of Big Data analytics is to help organisations find ways and means to save costs by improving their products / services delivery. As the banks collect large amount of customer data, so they can analyse that data to implement cost reductions (Keshetri, 2016). If the Banks can reduce their costs of operations, they may be able to pass on the savings in the form of reduced fees and processing charges. Therefore, we inquired from respondents about how Big Data analytics can help in costs reductions for the organisations offering credit card products.

\section{H. Improve Customers' Credit Evaluation}

Customer evaluation is vital to the success of loan products. Bank policies typically stipulate procedures to evaluate customers abilities to pay back the money lended to them (China Daily, 2004). Big Data analytics can help in improving Banks' capabilities to evaluate the credit worthiness of the potential customers. Further, Big Data analytics can also help setting up credit limits for the customers thereby reducing the risks of default. With that in view, we sought to understand from our respondents as to how Big Data analytics is helping or can help in improving customers' credit worthiness.

\section{REDUCE Risk Of Customer Default}

Banks need to protect themselves from the possible default by the customers. Reducing risks involved in lending practices is vital for the profitability of banks (Spotfire Blogging Team, 2013). Banks can use Big Data analytics to analyse what causes customer default and which type of customer are prone to default more than others. Such an understanding can help banks in reducing potential customer default. This study, therefore, sought to inquire from the respondents how banks can use Big Data technology in reducing risks of customer default and how that can be done.

\section{J. Innovate And Offer Tailored Products}

The growth of online technologies has changed the dynamics of market. With little to no barrier to entry, markets have become much more competitive. Banks also feel the market pressure with several non-baking businesses offering credit card facilities with attractive promotional offers. Banks, therefore, need to innovate and tailor products to needs of different segments of customers (Manyika et al., 2011). Big Data technology can help banks in seeking to understand the needs of their customers and then develop innovative and tailored credit card products. We inquired from 
our respondents whether Big Data technology is being used and how can be used to innovate credit card offerings and develop products tailored to customers' needs.

\section{K. ImProve Accuracy Of Predicting Outcome Of Business Strategies}

Big Data analytics is expected to improve predictive capabilities of businesses. Banks operate in a dynamic business environment and have to implement strategies to deal with the changing needs of the market. However, strategy implementation is time consuming effort and cost considerable amount of investment. Therefore, to improve chances of implementing business strategies successfully, banks can use Big Data analytics to review the chances of their success. We, therefore, inquired from the respondents if they think that Big Data analytics can help in strategy implementation and how that can be done.

\section{Ensure Security Of Data Of Credit Card Customers}

Banks have responsibility towards their customer to protect data and ensure it is not misused or stolen for fraudulent purposes. Big Data analytics can help identify any loopholes that need to be plugged to ensure security of data is maintained. We, therefore, sought to understand from respondents whether and how Big Data is being used for ensuring security and confidentiality of customer data.

\section{Contributions}

This study contributes by extending knowledge for both theory and practice in unique ways. Theoretically, the study builds fundamental and basic knowledge on the implications of Big Data analytics on consumer finance which is largely unexplored. The theoretical knowledge gained by this study can be used for doing a cross-sectional study to generalize the findings.

The study will also help lay foundation for study of $\mathrm{BD}$ analytics in other directions in the banking and finance sector.

Managerially, the study is an important milestone in providing knowledge on how BD analytics can be used for implementation of credit card based financing in China. The results can be used for driving strategies and plan of action for setting the scene of credit card based innovation offerings. China is a large market and with growing urbanization trends, more and more people will choose credit card based finance. Hence understanding how BD analytics can help in growth of consumer portfolio is important and hence the significance of the study.

\section{LIMITATIONS}

Being the exploratory study, we will be only accessing a small number of respondents. So generalization of results shall be done with caution.

Another limitation is that the limited availability of experts could influence the outcome of the study and generalisation of results. Since most of the respondents will be Chinese so communication and translation of data from Chinese to English language could also entail some limitations. 
International Journal of Managing Information Technology (IJMIT) Vol.9, No.3, August 2017

\section{EXPECTED OUTCOMES}

We expect to establish how BD analytics could be used for improving decision making processes in relation to consumer finance product offerings. The study will focus on understanding the characteristics of products, their features and benefits, ease of use, after sales services and cost of using the products. The results are expected to show the implications for both product / service providers and consumers, thus identifying areas that have synergies and how to exploit those synergies.

The questionnaire will include questions on issues involving how Big Data analytics will help in developing new credit card products, new distribution channels, developing strategies for improving credit card offerings.

\section{Conclusion}

While big data analytics may lead to competitive pressure to financial institutions, it also offers opportunities to enhance business performance and expand the efficiency of product / service offerings. Big data implications on consumer finance is expected to be beneficial to financial institutions in improving the relationship between consumers and card issuers, avoiding potential risk of overdue payment, developing innovating products, increasing work efficiency and expanding business scales. Banks in China are more likely to leverage upon the opportunities of big data analytics in establishing online consumer centers and developing insights on consumer behaviors thus improve business administration and long-term credit card supply strategies. This study therefore contributes to enrich our knowledge on big data implication on consumer finance especially for credit card offerings in China

\section{REFERENCES}

[1] Bagchi, S. (2014). Data analytics to play a key role in banks' growth. Available at http://www.cxotoday.com/story/data-analytics-to-play-a-key-role-in-banks-growth/ [Accessed 12 Nov. 2016].

[2] China Daily. (2004). Banks target nation's lucrative consumer finance market. Available at http://www.china.org.cn/english/BAT/90357.htm [Accessed 7 Nov. 2016].

[3] China Daily. (2015). China credit card transactions hit 15.2t yuan in 2014. Available at http://www.chinadaily.com.cn/business/2015-07/29/content_21440258.htm [Accessed 7 Nov. 2016].

[4] Crosman, P. (2012). 9 Big data challenges banks face. Available at http://www.americanbanker.com/issues/177_157/nine-big-data-challenges-banks-face-10518181.html [Accessed 7 Nov. 2016].

[5] Elan Financial Services. (nd). Developing a credit card strategy leveraging big data. Available at http://www.creditunions.com/articles/developing-a-credit-card-strategy-leveraging-bigdata/\#ixzz4OSRY2Ggw [Accessed 7 Nov. 2016].

[6] Fang, B., \& Zhang, P. (2016). Big Data in Finance. In Big Data Concepts, Theories, and Applications (pp. 391-412). Springer International Publishing.

[7] Gascon, D. (2015). Getting the most out of big data. Available at http://www.computerworld.com/article/2912441/big-data/getting-the-most-out-of-bigdata.html?nsdr=true\#tk.ctw-infsb [Accessed 7 Nov. 2016].

[8] Goernfedlt, T. (nd). Big data in finance can improve retention and returns. Available at https://insights.samsung.com/2016/03/28/big-data-in-finance-can-improve-retention-and-returns/ [Accessed 7 Nov. 2016].

[9] Groll, T., O’Halloran, S., Maskey, S., McAllister, G., \& Park, D. (2015). Big

Data and the regulation of banking and financial services. Bank Financial Services Policy Report, 34(12), 1-10.

[10] Hilal, A. H. and Alabri, S. S. (2013). Using Nvivo for data analysis in qualitative research. International interdisciplinary journal of education. Vol. 2, No. 2, pp. 181-186. 
International Journal of Managing Information Technology (IJMIT) Vol.9, No.3, August 2017

[11] Hughes, A. M. (2016). How to retain credit card customers. Available at http://www.dbmarketing.com/articles/Art175.htm [Accessed 7 Nov. 2016].

[12] Jiang, X. (2015). ICBC to accelerate internet strategy. Available at http://www.chinadaily.com.cn/business/2015-03/25/content_19909019.htm [Accessed 16 Nov. 2016].

[13] Jiang, X. (2016). Banks fight back in the consumer finance market. Available at http://www.chinadaily.com.cn/bizchina/2016-09/26/content_26892306.htm [Accessed 7 Nov. 2016].

[14] Kambatla, K., Kollias, G., Kurma, V. and Grama, A. (2014). Trends in big data analytics. Journal of parallel and distributed computing. Vol. 74, No. 7, pp. 2561-2573.

[15] Keshetri, N. (2016). Big data's role in expanding access to financial services in China. International journal of information management. Vol. 36, No. 3, pp. 297-308.

[16] Kugel, R. (2013). Finance can get a big advantage from big data. Available at http://www.smartdatacollective.com/robert-kugel/168071/finance-can-get-big-advantage-big-data [Accessed 7 Nov. 2016].

[17] Li, J. (2012). Consumer finance set to boom in China. Available at http://www.chinadaily.com.cn/business/2012-09/12/content_15751947.htm [Accessed 7 Nov. 2016].

[18] Manyika, J., Chui, M., Brown, B., Bughin, J., Dobbs, R., Roxburgh, C. and Byers, A.H. (2011). Big data: The next frontier for innovation, competition and productivity. Available at http://www.mckinsey.com/business-functions/digital-mckinsey/our-insights/big-data-the-nextfrontier-for-innovation [Accessed 7 Nov. 2016].

[19] Marr, B. (2016). Big data in banking: How Citibank delivers real business benefits with its data-first approach. Available at http://www.forbes.com/sites/bernardmarr/2016/09/09/big-data-in-bankinghow-citibank-delivers-real-business-benefits-with-their-data-first-approach/3/\#220f798c13ca [Accessed 12 Nov. 2016].

[20] McMalcolm, J. (2015). Is big data helping improve consumer finance? Available at http://blog.ideacafe.com/big-data-helping-improve-consumer-finance [Accessed 7 Nov. 2016].

[21] Oracle. (2016). An enterprise architect's guide to big data. Available at

[22] http://www.oracle.com/technetwork/topics/entarch/articles/oea-big-data-guide-1522052.pdf [Accessed 7 Nov. 2016].

[23] Pivotal. (nd). China CITIC bank driving revenue and reducing risk. Available at https://pivotal.io/bigdata/case-study/china-citic-bank-driving-revenue-and-reducing-risk [Accessed 7 Nov. 2016].

[24] Pramanick, S. (2013). Analytics in banking services. Available at http://www.ibmbigdatahub.com/blog/analytics-banking-services [Accessed 12 Nov. 2016].

[25] Przoom. (2012). BRIC data Publishes Emerging Opportunities in the Chinese Consumer Finance Market. Available at http://www.przoom.com/news/114563/ [Accessed 7 Nov. 2016].

[26] Rouse, M. (2014). Big data analytics. Available at http://searchbusinessanalytics.techtarget.com/definition/big-data-analytics [Accessed 7 Nov. 2016].

[27] Sen, A. (2014). Banking on big data analytics. Available at http://www.livemint.com/Industry/F5uNVbogJfsNB7cSt1 toBL/Banking-on-Big-Data-analytics.html [Accessed 12 Nov. 2016].

[28] Spotfire Blogging Team. (2013). Big data analytics to mitigate risk in banking, insurance. Available at http://www.tibco.com/blog/?p=20587\&utm_source=tuicool\&utm_medium=refe rral [Accessed 7 Nov. 2016].

[29] Yao, M. (2014). Big opportunities in China to mine big data. Available at http://www.shanghaidaily.com/feature/news-feature/Big-opportunities-in-China-to-mine-bigdata/shdaily.shtml [Accessed 7 Nov. 2016] 